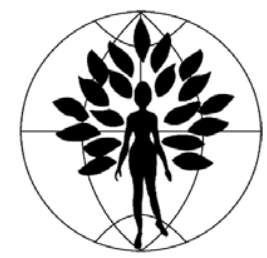

\title{
World Report on Women's Health 2006
}

We should like to call the attention of our readers to the World Report on Women's Health 2006, edited by Guest Editors Dorothy Shaw and Louis G. Keith, which was published as the September issue of the International Journal of Gynecology and Obstetrics (Int J Gynecol Obstet 2006; 94:207-394). The importance of this publication was highlighted in remarks made by Dr. Shaw, President of the International Federation of Gynecology and Obstetrics (FIGO), at the press conference to introduce the Report, on Monday, November 6, 2006, at the XVIII FIGO World Congress in Kuala Lumpur, Malaysia. The following are Dr. Shaw's remarks:

The Millennium Development Goals (MDGs) represent a commitment of 189 member states that adopted them during the Millennium Summit in September 2000. This UN General Assembly recognized that gender equality and women's empowerment are both central to achieving sustainable development by means of combating poverty, hunger and disease. Neither reproductive nor sexual health was explicitly articulated in the original MDGs and indicators - a critical omission, as, globally, women are more disadvantaged than men. However, a clear link exists between all of the MDGs and the reproductive and sexual health of women, who cannot contribute to sustainable development, unless their right to health is met through improved access. The FIGO World Report on Women's Health 2006 addresses many issues critical to the success of the MDGs, with a focus on how partnerships have become a crucial vehicle to improve access to health for women.

It is no accident that of the 21 chapters in the report, 9 of them are focused directly or indirectly on maternal mortality. A woman dies every minute from a pregnancyrelated cause and 30 more suffer serious consequences, including obstetric fistula. Millennium Goal 5 calls for a reduction of three-quarters in maternal deaths globally by 2015. The World Report focuses on the common causes: lack of human resources, one of the most serious problems; lack of a systematic approach to identifying key areas requiring attention; postpartum hemorrhage - the most common cause of maternal deaths, followed by unsafe abortion, accounting for $13 \%$ of deaths. There is a clear link between the factors that result in high maternal mortality rates. The solutions are not complex, and include access to emergency contraception, as well as modern methods of fertility regulation, especially for young people, since almost $50 \%$ of the world's population is under age 25. Most problems are related to poverty and lack of respect for women and girls. The solutions will require partnerships and political commitment, based on the well-known available evidence. Many solutions are identified in this report. Stigma is a common thread in many challenges faced by women, including women's mental health, a silent cause of mortality and morbidity.

Legal challenges are being increasingly and successfully brought against governments of some countries when they lack transparency and violate the rights of women to access health care because women are not considered full citizens under the law.

Women's rights also include the right to a healthy newborn, yet 4 million newborns are dying each year around the world. The newborn has not been the focus of attention, yet very simple techniques can dramatically improve survival. Breastfeeding of infants is also highlighted in the Report as a life-saving practice, often not promoted by health professionals. Infections such as malaria and HIV affect women and children disproportionately, causing mortality or serious illness directly and indirectly; two chapters cover these topics.

HIV/AIDS has become a disease with a woman's face, with the majority of infections in young people being women, as high as 75\% in some African countries. Another infection that causes cancer, HPV, is highlighted in terms of its prevention by a new vaccine, as well as screening women and treating them for the cancer before it becomes fatal.

The Report also addresses some of the controversial issues of today: cesarean section by choice; access to in vitro fertilization; and sex trafficking in South Asia. One of the most important chapters highlights gender-based violence another public health problem affecting girls and women in all social strata in all countries of the world. Examples include prenatal sex selection; neglect of girls; honor and dowry-related violence; trafficking of women and girls for sexual exploitation; female genital mutilation/cutting; and violence against women in situations of armed conflict. There are serious health consequences for the women, including adverse outcomes of pregnancy. Costs to the health care system are enormous, estimated at 3.3\% Gross Domestic Product in the USA and 40.2 billion USD in England and Wales. 
Recent information indicates that almost $50 \%$ of sexual assaults occur in girls under age 15, and this may be a factor in the disturbing increase in HIV prevalence in young women aged 15-24, who now account for the majority of HIV positive young people. Public awareness is the first step in addressing these gross violations of the human rights of women and girls.

The Report represents dedicated efforts by many authors and organizations devoted, as is FIGO, to the wellbeing of women and children worldwide, and financial support was provided by the following generous sponsors: Ipas, working in collaboration with the UK Department of International Development, the International Planned Parenthood Federation, the Japanese Society of Obstetrics and Gynecology, the Society of Obstetricians and Gynaecologists of Canada, the Department of Reproductive Health and Research of the World Health Organization, and the Royal Australian and New Zealand College of Obstetricians and Gynaecologists.

It is our sad task to mention that one of the authors, Dr. Suman Mehta at UNAIDS, died suddenly in late 2006 and was unable to share in the launch of the Report. We are grateful for her contribution and express sadness for her family, friends, and the world of women's health.

We share the hope of Dr. Shaw and Dr. Keith, of the FIGO Officers and Board, and of the generous sponsors, that the World Report on Women's Health 2006, Women's Right to Health and the Millennium Development Goals: Promoting Partnerships to Improve Access, will be widely read and cited.

J.J. Sciarra

International Journal of Gynecology and Obstetrics, Northwestern University Medical School,

Chicago, IL, USA

E-mail address: jsciarra@northwestern.edu.

T.R.B. Johnson

International Journal of Gynecology and Obstetrics, University of Michigan, Ann Arbor, MI, USA 